Himat Vaghadia MB BS MHSC FCA FRCPC, ${ }^{*} \dagger$

Michael A. Solylo BSc MD FRCPC, *

Cynthia L. Henderson MD FRCPC, *

G.W.E. Mitchell MB CHB FRCOG FRCS(Ed) FRCSC $\ddagger$

\section{Selective spinal anesthesia for outpatient laparoscopy. II: Epinephrine and spinal cord function}

Purpose: To compare two small-dose solutions (with and without epinephrine) for spinal anesthesia during outpatient laparoscopy and to determine spinal cord function with these low-dose solutions.

Method: Twenty outpatients undergoing gynecological laparoscopy were randomly assigned to receive spinal anesthesia with one of two low dose solutions. Group LS- 10 mg lidocaine plus $10 \mu$ g sufentanil; Group LSE- 10 mg lidocaine plus $10 \mu \mathrm{g}$ sufentanil plus epinephrine $50 \mu \mathrm{g}$. Solutions were diluted to three millilitres with sterile water for injection. A 27-gauge Whitacre needle was inserted at $L_{2-3}$ or $L_{3-4}$ in the sitting position. Operating conditions and spinal cord function (spinothalamic, dorsal column and motor) were assessed.

Results: Operating conditions were good - excellent in both groups. The incidence of shoulder tip discomfort, pruritus and nausea, and the amount of supplementation with alfentanil and midazolam was not different between groups. Most patients in both groups had preserved dorsal column function and normal motor power on arrival in PACU and were able to satisfy 'walk out' criteria. Recovery of pinprick sensation and discharge times were not different. Mild pruritus (VAS score $\leq 5$ ) was present in both groups.

Conclusion: For short duration laparoscopy, addition of $50 \mu \mathrm{g}$ epinephrine to a small dose of spinal $10 \mathrm{mg}$ lidocaine with $10 \mu \mathrm{g}$ sufentanil did not provide additional benefit in terms of intraoperative analgesia or operating conditions. Spinal cord function was preserved with small-dose techniques.

Objectif : Comparer des solutions de médicaments à faibles doses (avec et sans épinéphrine) utilisées pour la rachianesthésie pendant la laparoscopie ambulatoire et déterminer leur influence sur la fonction médullaire.

Méthode : Vingt patientes devant subir une laparoscopie gynécologique ambulatoire ont été réparties en deux groupes : le groupe LS a reçu $10 \mathrm{mg}$ de lidocaïne et $10 \mu \mathrm{g}$ de sufentanil; le groupe LSE a reçu $10 \mathrm{mg}$ de lidocaiine, $10 \mu \mathrm{g}$ de sufentanil et $50 \mu \mathrm{g}$ d'épinéphrine. Les solutions ont été complétées à trois millilitres avec de l'eau stérile injectable. Une aiguille Whitacre $27 \mathrm{G}$ a été insérée à $L_{2-3}$ ou à $L_{3-4}$ en position assise. Les conditions de l'opération et la fonction médullaire (spino-thalamique, colonne thoracique et fonction motrice) ont été évaluées.

Résultats : Chez les patientes des deux groupes, les conditions de l'opération ont été de bonnes à excellentes, l'incidence de malaise à l'épaule, de prurit et de nausées, ainsi que la quantité d'alfentanil et de midazolam administrés comme analgésie supplémentaire ont été similaires. Chez la majorité des patientes, la fonction de la colonne thoracique et l'activité motrice normale étaient intactes à l'arrivée en salle de réveil, ce qui a permis aux patientes de quitter le service. La récupération de la sensibilité à la douleur et le moment du congé n'ont pas différé d'un groupe à l'autre. Un prurit modéré ( 5 à l'EVA) a été noté dans les deux groupes.

Conclusion : L'addition de $50 \mu \mathrm{g}$ d'épinéphrine à une faible rachianesthésie composée de $10 \mathrm{mg}$ de lidocaïne et de $10 \mu \mathrm{g}$ de sufentanil, pour une laparoscopie de courte durée, n'apporte pas d'avantages supplémentaires à l'analgésie peropératoire et n'améliore pas les conditions de l'opération. La fonction médullaire est préservée avec I'utilisation de techniques à faibles doses.

From the Departments of Anesthesia, ${ }^{\star}$ Health Care and Epidemiology, $†$ and Gynaecology, $\ddagger$ Vancouver General Hospital, University of British Columbia, Vancouver, BC, Canada.

Address correspondence to: Dr. Himat Vaghadia, The Department of Anesthesia (Room 3200), Vancouver General Hospital, 3rd Floor 910 West 10th Ave, Vancouver, BC, V5Z 4E3 Canada. Phone: 604-875-4304; Fax: 604-875-5209; E-mail: hvaghadi@vanhosp.bc.ca Accepted for publication October 29, 2000. 
I $\mathrm{N}$ a previous study ${ }^{1}$ we demonstrated that a hypobaric solution of $10 \mathrm{mg}$ lidocaine $1 \%$ mixed with $10 \mu \mathrm{g}$ sufentanil and sterile water to $3 \mathrm{ml}$, provided selective spinal anesthesia with preserved touch and proprioception during and after laparoscopic surgery in outpatients. Surgical conditions were good to excellent and most patients were able to achieve 'walk out' criteria at the conclusion of surgery. The addition of epinephrine to spinal anesthetics enhances analgesia after gynecologic surgery ${ }^{2}$ and improved tolerance to surgical stimuli with a small dose of bupivacaine in volunteers. ${ }^{3}$

The purpose of the present study was to evaluate whether addition of $50 \mu \mathrm{g}$ epinephrine to our smalldose hypobaric spinal solution would provide superior analgesia and intraoperative conditions without delaying return of spinal cord function. A secondary objective was to allow spinal cord functional assessment with small-dose spinal techniques.

\section{Methods}

The study was designed as a randomized, double blind, controlled trial and had approval from the Clinical Screening Committee for Research and Other Studies of the University of British Columbia. Twenty ASA physical status I and II women scheduled for outpatient laparoscopy were enrolled. To be included, patients were required to have chosen spinal anesthesia, given written consent and have no contraindications to any of the anesthetic agents. Patients were excluded if they had evidence of neurological or neuromuscular diseases, infection at the intended site of spinal needle insertion, hypersensitivity to amide local anesthetic, epinephrine or sufentanil. Patients were randomly assigned to receive one of two spinal anesthetic solutions:

Group LS - 10 mg lidocaine 1\% (1 ml, Astra Zeneca, Mississauga, Ontario, Canada), mixed with $10 \mu \mathrm{g}$ sufentanil $(0.2 \mathrm{ml})$ and sterile water $(1.8 \mathrm{ml})$.

Group LSE - $10 \mathrm{mg}$ lidocaine $1 \%(1 \mathrm{ml})$, mixed with $10 \mu \mathrm{g}$ sufentanil $(0.2 \mathrm{ml}), 50 \mu \mathrm{g}$ epinephrine and sterile water $(1.8 \mathrm{ml})$.

Both mixtures had a specific gravity of 1.002 as determined by a refractometer (American Optical Company, Chicago, USA).

All spinal solutions were prepared aseptically by an anesthesiologist who was not involved with the study following instructions in sealed randomization envelopes. Patients, investigators, surgeons and nurses were blinded to the study. All patients had an intravenous cannula inserted in the preoperative lounge and $1 \mathrm{~L}$ of normal saline infusing although no specific preload was given. All patients walked into the oper- ating room unassisted. Upon arrival, routine monitors were applied (ECG, automatic blood pressure and pulse oximeter). The spinal anesthetic was administered by a standardized technique. With the patient in sitting position, a midline approach at $\mathrm{L}_{2-3}$ or $\mathrm{L}_{3-4}$ was used after subcutaneous local anesthetic infiltration with lidocaine 1\%. A 27-gauge Whitacre point spinal needle (Becton Dickinson, Franklin Lakes, NJ) was inserted with the orifice pointing cephalad and without the aid of an introducer. The spinal solution was injected rapidly $\left(0.5 \mathrm{ml} \cdot \mathrm{sec}^{-1}\right) .4$ After one minute, patients were placed in reverse Trendelenburg position (15-20) until the level of sensory anesthesia (tested to pinprick) reached $\mathrm{T}_{6}$. During this interval (approximately 5-8 min) the patient's legs were placed in lithotomy stirrups and, the perineum and abdomen were prepared. Patients breathed room air throughout the procedure and in the PACU unless their oxygen saturation decreased to $<93 \%$. All spinals were inserted by the same blinded anesthesiologist (MAS) who also undertook all intraoperative care and assessments and, PACU assessments.

A standardized surgical technique was used for laparoscopy. Before insufflation of the abdomen with $\mathrm{CO}_{2}$, the OR table was returned to the horizontal position to minimize the amount of $\mathrm{CO}_{2}$ collecting under the patient's diaphragm. Three to four litres $\mathrm{CO}_{2}$ were insufflated followed by insertion of infra-umbilical and suprapubic trocars and ports. Shoulder tip pain (referred from the effects of $\mathrm{CO}_{2}$ on the peritoneal surface of the diaphragm) was treated with intravenous 250-500 $\mu \mathrm{g}$ increments alfentanil. Midazolam, 1-2 mg $i v$, was administered for sedation if necessary.

Sensory block was determined by pinprick with an 18-gauge needle, ice (temperature sensation), and light touch was assessed with a fine tip of paper tissue (Kleenex ${ }^{\circledR}$,Kimberley-Clark Corporation, USA). Proprioception was tested at the big toe. Motor block was assessed with a modified Bromage scale ${ }^{1-2}$ :

$\mathrm{l}=$ complete motor block;

$2=$ able to move feet only;

$3=$ able to move feet and knees;

$4=$ able to perform a straight leg raise;

$5=$ able to perform a 'deep knee bend'.

Observations were made at $3,5,30,45,60,75$ and 90 min after spinal injection. Deep knee bends could not be assessed at three and five minutes because the patient was being prepared for surgery. Surgical conditions and side effects such as shoulder tip pain, nausea and pruritus were also documented.

In the PACU, the following assessments were made on arrival and at every 15 min intervals: pinprick level, level to ice, light touch, vibration sense (present or 
absent) was tested at the medial malleolus with a tuning fork $(128 \mathrm{~Hz})$, distal joint proprioception, two point discrimination, deep tendon reflexes were tested at the knees and ankles, coordination in the supine position was tested with a heel-to-shin test and motor block was graded as above. In patients who had achieved a motor block recovery score of 5 , we performed Romberg's test followed by heel to toe walking along a straight line. Patients who satisfied the following criteria were considered fit to ambulate: a) Motor recovery score of 5 ; b) normal vibration sense; c) normal touch sensation; d) normal joint proprioception; e) normal heel-shin test; and f) normal or slightly decreased ankle and knee reflexes, g) normal Romberg's test. Pruritus was assessed by means of a VAS scale anchored at 0 (no pruritus) and 10 (maximum pruritus). Blood pressure and heart rate were recorded in supine position every $15 \mathrm{~min}$ in the PACU and in standing position in those patients who were deemed fit to ambulate.

Patients were discharged from the PACU after meeting the following standard discharge criteria:

1) oriented;

2) stable vital signs;

3) no surgical complications (e.g., bleeding);

4) absence of side effects (e.g., vomiting);

5 ) adequate pain control with oral analgesics; and

6) resolution of motor block, sensory block $\leq \mathrm{S} 2$ (able to ambulate and dress unassisted).

Sample size was chosen after consultation with the hospital epidemiology department. Allowing for an $\alpha$ of 0.05 and a $B$ of 0.2 it was estimated that a sample size of 10 per group would be sufficient to identify a difference of $50 \%$ assuming a standard deviation of 20 min. It was felt that smaller difference would not be clinically relevant in terms of changing our practice.

Statistical analysis was performed using the SPSS system (version 4.0). Continuous and numerical data were tested for normality using the Martinez-Iglewicz, the Kolmorgorov-Smirnov and the D'Agostino-Pearson Omnibus $\mathrm{K}^{2}$ tests. Skewed data were summarized as median(range) and analyzed for between group differences using Kruskal-Wallis tests. Categorical data were analysed by Chi-square or Fisher exact test as appropriate. Bonferroni's correction was applied for multiple corrections. A value of $P<0.05$ was considered significant.

Results

Twenty ASA I-II patients were enrolled in the study and both groups were comparable with respect to demographics (Table I). Intraoperative outcomes are shown in Table II. There were no differences in the amount of supplemental midazolam or alfentanil
TABLE I Demographic data

\begin{tabular}{lll}
\hline & Group LS & Group LSE \\
\hline $\mathrm{n}$ & 10 & 10 \\
Age $(\mathrm{yr})$ & $34 \pm 8$ & $36 \pm 5$ \\
Weight $(\mathrm{kg})$ & $64 \pm 9$ & $62 \pm 12$ \\
Height $(\mathrm{cm})$ & $164 \pm 7$ & $162 \pm 8$ \\
Surgery & & \\
Tubal cautery & 4 & 3 \\
Tubal clips & 3 & 1 \\
Dye-pertubation & & 1 \\
$\begin{array}{l}\text { Other } \\
\text { \# of Spinal attempts: }(1 / 2 / 3)\end{array}$ & 3 & 5 \\
Level of Spinal: & $6 / 3 / 1$ & $8 / 1 / 1$ \\
$\mathrm{~L}_{2-3}$ & 5 & 8 \\
$\mathrm{~L}_{3-4}$ & 5 & 2 \\
Duration of surgery $(\mathrm{min})$ & $19 \pm 11$ & $26 \pm 12$ \\
\hline
\end{tabular}

Values are counts or means \pm SD.

TABLE II Intraoperative outcomes.

\begin{tabular}{lll}
\hline & Group LS & Group LSE \\
\hline $\begin{array}{l}\text { Surgical conditions: } \\
\text { Excellent/Good/Poor }\end{array}$ & 10 & 10 \\
$\begin{array}{l}\text { Shoulder tip pain: } \\
\text { None/Mild/moderate/severe }\end{array}$ & $9 / 1 / 0$ & $7 / 2 / 1$ \\
$\begin{array}{l}\text { Abdominal discomfort: } \\
\text { None/mild/moderate/severe }\end{array}$ & $4 / 3 / 1 / 2$ & $5 / 2 / 3 / 0$ \\
Supplementation: & $8 / 2 / 0$ & $8 / 0 / 2 / 0$ \\
$\begin{array}{l}\text { Alfentanil: } \\
250 \mu g\end{array}$ & 4 & \\
$500 \mu g$ & 3 & 6 \\
Midazolam: & & \\
$1 \mathrm{mg}$ & 2 & 5 \\
$1.5 \mathrm{mg}$ & 1 & 2 \\
$2 \mathrm{mg}$ & 4 & \\
\hline
\end{tabular}

Values are counts.

required. All patients were successfully operated upon and surgical conditions were rated as good to excellent. One patient in Group LSE had to be converted to general anesthesia at the request of the surgeon because of technical difficulties in visualizing the right ovary. Two patients in Group LS described their shoulder tip discomfort as 'severe', but this was easily managed with supplemental adjuvants. Two patients in each group experienced moderate abdominal discomfort from intraperitoneal $\mathrm{CO}_{2}$. Postoperative recovery of spinal cord function is summarized in Table III. Vibration sense and 2 point discrimination were present on arrival in PACU in all patients of Group LS and within $15 \mathrm{~min}$ in Group LSE. Proprioception was present in all patients in both groups. Most patients in both 
TABLE III Postoperative recovery of spinal cord function.

\begin{tabular}{|c|c|c|}
\hline & Group LS & Group LSE \\
\hline Time to discharge from $\mathrm{PACU}(\mathrm{min})$ & $89 \pm 18$ & $103 \pm 23$ \\
\hline \multicolumn{3}{|l|}{ Normal vibration sense $(\mathrm{n})$ : } \\
\hline Arrival in PACU & 10 & 8 \\
\hline$+15 \min$ & 10 & 10 \\
\hline \multicolumn{3}{|l|}{ Normal proprioception $(\mathrm{n})$ : } \\
\hline Arrival in PACU & 10 & 10 \\
\hline \multicolumn{3}{|l|}{ Normal 2 point discrimination $(\mathrm{n})$ : } \\
\hline Arrival in PACU & 10 & 9 \\
\hline$+15 \min$ & 10 & 10 \\
\hline \multicolumn{3}{|l|}{ Normal Knee Reflex (n): } \\
\hline Arrival in PACU & 8 & 8 \\
\hline$+15 \min$ & 8 & 9 \\
\hline$+30 \mathrm{~min}$ & 8 & 9 \\
\hline$+45 \mathrm{~min}$ & 8 & 9 \\
\hline$+60 \mathrm{~min}$ & 8 & 9 \\
\hline$+90 \mathrm{~min}$ & 8 & 9 \\
\hline \multicolumn{3}{|l|}{ Normal Ankle Reflex (n): } \\
\hline Arrival in PACU & 8 & 8 \\
\hline$+15 \min$ & 8 & 8 \\
\hline$+30 \mathrm{~min}$ & 8 & 9 \\
\hline$+45 \mathrm{~min}$ & 8 & 9 \\
\hline$+60 \mathrm{~min}$ & 8 & 9 \\
\hline$+90 \min$ & 8 & 9 \\
\hline \multicolumn{3}{|l|}{ Normal heel-shin test $(\mathrm{n})$ : } \\
\hline Arrival in PACU & 10 & 10 \\
\hline \multicolumn{3}{|l|}{ Normal Romberg test $(\mathrm{n})$ : } \\
\hline Arrival in PACU & 8 & 8 \\
\hline$+15 \min$ & 9 & 8 \\
\hline$+30 \mathrm{~min}$ & 9 & 9 \\
\hline$+45 \mathrm{~min}$ & 10 & 10 \\
\hline
\end{tabular}

Values are count or mean \pm SD.

groups had normal deep tendon reflexes (knee and ankle). Two patients in Group LS and one patient in Group LSE had slightly decreased reflexes. All patients were able to perform a normal heel-shin test on arrival in PACU and a normal Romberg's test within $45 \mathrm{~min}$ of arrival into PACU. There was no significant difference in the time to discharge from PACU between the groups. Recovery of sensory block to pinprick was not different between the two groups and is summarized in Figure 1. Sensory levels to ice (temperature) and light touch were identical to pin prick over time and there was no difference between groups. All patients had preserved touch and consequently were able to feel the surgeon preparing the abdomen and perineum. Pruritus scores were $<5$ in both groups over time and there was no difference between the groups (Figure 2). Most patients satisfied 'fit to ambulate' criteria on arrival to PACU (Figure 3). Blood pressure and heart rate were not significantly different between groups and between supine and standing position in those patients who were able to ambulate.

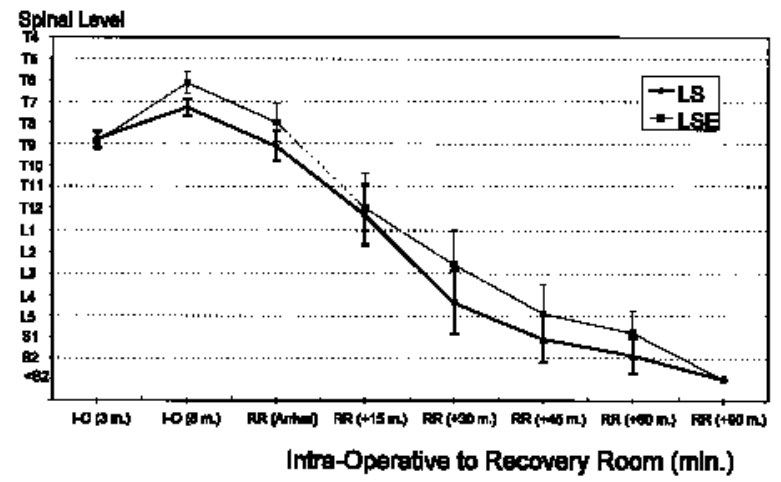

FIGURE I Change in sensory level to pinprick over time. There was no difference between group LS and LSE. Values are means \pm $\mathrm{SE}$. $\mathrm{I}-\mathrm{O}(3 \mathrm{~min})=$ intraoperative $3 \mathrm{~min}$ post spinal injection. $\mathrm{RR}=$ arrival in PACU. RR $(+15 \mathrm{~min})=15 \mathrm{~min}$ post arrival in PACU.

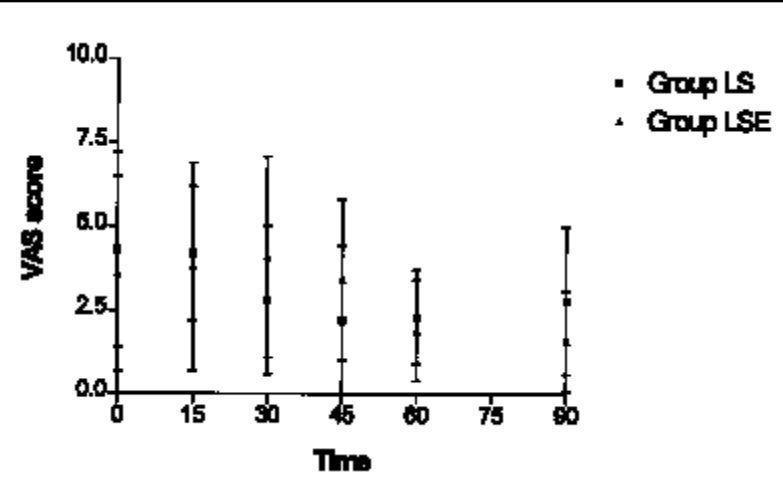

$\overline{\text { FIGURE } 2 \text { VAS score }(\text { mean }+ \text { SD) for pruritus over time. Time }}$ $0=$ arrival in PACU.

Discussion

This study has shown that when small-dose selective spinal anesthesia is performed with $10 \mathrm{mg}$ hypobaric lidocaine $1 \%$ mixed with $10 \mu \mathrm{g}$,sufentanil, the addition of $50 \mu \mathrm{g}$ epinephrine did not confer any benefit in terms of intraoperative patient comfort nor did it delay recovery of spinal cord function. Operating conditions were judged good-excellent in both groups and most patients had minimal motor block, preserved touch and proprioception. Dorsal column function was preserved in most patients and a majority of patients were able to achieve 'fit to ambulate' criteria on arrival in PACU.

In a previous study we demonstrated that selective spinal anesthesia (SSA) was a viable technique for outpatient gynaecologic laparoscopy procedures and that 


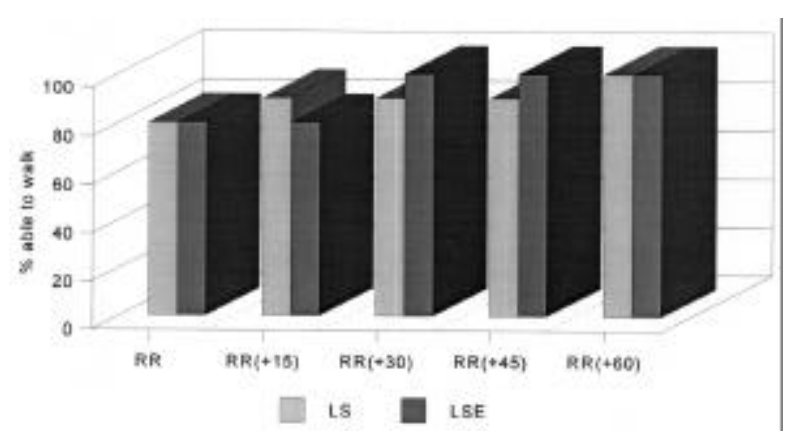

FIGURE 3 Motor block (\% able to walk) on arrival in PACU $(\mathrm{RR})$ and at $15 \mathrm{~min}$ intervals thereafter.

a majority of patients were capable of achieving 'walk out' criteria at the end of surgery. ${ }^{1}$ The theoretical advantage of a 'walk in walk out' spinal anesthetic technique in outpatients would be the ability to bypass PACU and possibly discharge the patient early. However, it is difficult to attest to the safety of walking immediately after a spinal anesthetic unless a detailed assessment of spinal cord function can be made. In this study we have demonstrated that spinal cord function appears to be preserved with small-dose selective spinal anesthesia. Our study shows that dorsal column function (vibration sense, distal joint proprioception, heel-shin test and Romberg's test) was intact in most $(80 \%)$ patients after SSA and, the addition of a small dose of epinephrine did not have a significant effect. With the observed standard deviations in this study, the sample size was found to have a power of $80 \%$ to identify differences of $\geq 27 \mathrm{~min}$. Differences smaller than these could well be missed with such a sample size but would not have been clinically relevant in our practice. This study also provided an opportunity to acquire more information on spinal cord function with SSA.

Normal lower limb motor function and power are essential for balance and ambulation. Seventy percent of patients in both groups were 'fit to ambulate' on arrival in PACU. The rest were able to do so within 60 min of arrival in PACU. In retrospect, the global criteria used to define fitness to walk were probably too strict. Patients who did not satisfy our criteria failed because their knee and ankle reflexes were judged to be slightly decreased (two patients in group LS and one patient in group LSE). However, assessment of reflexes is subjective and it is difficult to make fine distinctions between normal versus abnormal reflexes. In the present study, since these three patients met all the other criteria for ambulation, they were classified as 'fit to ambulate.' In obstetric anesthetic practice, testing for ankle and knee reflexes is not considered a prerequisite for ambulation during extradural/intrathecal analgesia in labour. ${ }^{5}$ We have also confirmed obstetric studies by showing that small doses of intrathecal agents spare both motor and proprioceptive fibres. ${ }^{6}$ This effect is consistent with the dynamics of local anesthetic penetration and nerve fibre diameter- both motor and proprioceptive fibres are similar in diameter $(12-20 \mu \mathrm{m}) . .^{7}$ On the other hand, pain sensation is mediated by the $\mathrm{A} \delta(2-5 \mu \mathrm{m})$ and the smaller $\mathrm{C}(0.3$ $1.3 \mu \mathrm{m})$ fibres that are more susceptible to local anesthetic block as found in this study. All patients in the study had preserved touch sensation and were aware of surgical preparation of the abdomen and perineum. However, we were able to demonstrate a sensory level identical to pinprick and ice when patients were tested for light touch with paper tissue. This would suggest that touch is mediated by two fibre types - light touch by the A $\delta$ fibres, and regular touch sensation, such as surgical preparation and touching with a gauze swab (as in our previous study ${ }^{\mathrm{l}}$ ), by the larger $\mathrm{A} ß(5-12 \mu \mathrm{m})$ fibres. Presumably, both solutions in this study were able to block the smaller $A \delta$ without the larger $A B$ fibres. Alternatively, the sensation of surgical preparation could be a 'pressure' sensation which is also mediated by the larger $A ß$ fibres.

One surprising finding of this study was the absence of postural hypotension when subjects assumed the upright position. All patients who were able to stand had, at that time, evidence of pin prick analgesia $\leq \mathrm{Tl} 0$, suggesting that the A $\delta$ fibers were still blocked. By inference this suggests that the smaller B and C fibres, responsible for autonomic function, would be blocked and result in some degree of postural hypotension. One explanation for the absence of postural hypotension may be that the bulk of sympathetic outflow is from the thoracic spinal cord and our small dose solutions do not contribute to a high thoracic block. Our findings of a lack of hypotension are also in agreement with those of Buggy et al., who demonstrated that, in labouring women with an extradural block, there was no difference in standing and recumbent arterial pressure even though pin prick analgesia, and impaired posterior column function were detectable. ${ }^{5}$ Another explanation may be that sympathetic recovery occurred before the other modalities as has been shown with previous studies of spinal anesthesia. ${ }^{8}$ It appears that the sequence of return of function after spinal anesthesia is not a simple and predictable phenomenon. The two most common sequences of return of function appear to be a) 
motor-sensory-sympathetic and, b) sympatheticmotor-sensory. 9 A sequence of motor-sympatheticsensory may also occur but is less common. ${ }^{9}$

Safe ambulation requires normal dorsal column function and lower limb motor power as well as normal balance. Normal balance requires sensory input from somatosensory (skin, joint and muscle proprioception), visual and vestibular systems. Although all three systems exert variable influences on balance during walking, the dominant input is somatosensory from the lower limbs. In addition, deficiency of one input can be compensated by increased input from the other systems as shown by clinical experience in patients with diseases that impair one system. ${ }^{5,6}$ This suggests that ambulation after a small-dose spinal anesthetic which spares motor and dorsal column function, but selectively blocks the lateral spinothalamic tracts could be achieved with the help of compensatory inputs from other systems. Our study has confirmed that this is possible although no inferences can be made about safety of such practice. Future studies need to address this issue. However, the safety of walking epidurals in obstetrics suggests that a similar degree of success could be achieved with 'walking spinals' in outpatients.

All patients in both groups had mild self limiting pruritus (VAS score $<5$ ) that resolved without requiring pharmacological intervention. Epinephrine did not enhance pruritus, sensory or motor block or improve intraoperative analgesia.

In conclusion, we demonstrated that small-dose selective spinal anesthesia can be produced with a mixture of $10 \mathrm{mg}$ lidocaine $1 \%$ and $10 \mu \mathrm{g}$ sufentanil in sterile water. Addition of a small dose of epinephrine $(50 \mu \mathrm{g})$ did not improve surgical conditions, intraoperative analgesia or alter spinal cord functional recovery. Most patients satisfied 'fit to ambulate' criteria at the end of surgery.

\section{References}

I Vaghadia H, Vishari D, Mitchell GWE, et al. Selective spinal anesthesia for outpatient laparoscopy.

I: Characteristics of three hypobaric solutions. Can J Anesth 2000; 48: 256-60.

2 Goyagi T, Nishikawa T. The addition of epinephrine enhances postoperative analgesia by intrathecal morphine. Anesth Analg 1995; 81: 508-13.

3 Moore JM, Lin SS, Pollock JE, Neal JM, Knab JH. The effect of epinephrine on small-dose hyperbaric bupivacaine spinal anesthesia: clinical implications for ambulatory surgery. Anesth Analg 1998; 86: 973-7.

4 Horlocker TT, Wedel DJ, Wilson PR. Effect of injection rate on sensory level and duration of hypobaric bupiva- caine spinal anesthesia for total hip arthroplasty. Anesth Analg 1994; 79: 773-7.

5 Buggy D, Hughes N, Gardiner J. Posterior column sensory impairment during ambulatory extradural analgesia in labour. Br J Anaesth 1994; 73: 540-2.

6 Parry MG, Fernando R, Bawa GPS, Poulton BB. Dorsal column function after epidural and spinal blockade: implications for the safety of walking following lowdose regional analgesia for labour. Anaesthesia 1998; 53: 382-403.

7 Wildsmith JAW. Peripheral nerve and local anaesthetic drugs. Br J Anaesth 1986; 58: 692-700.

8 Pflug AE, Aasheim GM, Foster C Sequence of return of neurological function and criteria for safe ambulation following subarachnoid block (spinal anaesthetic). Can Anaesth Soc J 1978; 25: 133-8.

9 Das FG, Virtue $R W$. Sympathetic block persistence after spinal or epidural analgesia. JAMA 1963; 183: 285-7. 